\title{
Chemical and antimicrobial characterization of essential oils obtained from aerial part, root and fruit of Ferulago longistylis Boiss., an endemic species
}

Betül Demirci ${ }^{1}$, Elif Dilmaç ${ }^{2}$, Damla Kırcl ${ }^{1,3}$, Fatih Demirci ${ }^{1,4}$, Ceyda Sibel Kılıç ${ }^{5}$ Hayri Duman ${ }^{6}$, Ilhan Gürbüz ${ }^{2 *}$

${ }^{1}$ Department of Pharmacognosy, Faculty of Pharmacy, Anadolu University, 26470 Eskişehir, TURKEY

${ }^{2}$ Department of Pharmacognosy, Faculty of Pharmacy, Gazi University, 06330 Ankara, TURKEY

${ }^{3}$ Department of Pharmacognosy, Faculty of Pharmacy, Selçuk University, 42250 Kampus-Konya, TURKEY

${ }^{4}$ Faculty of Pharmacy, Eastern Mediterranean University, 99450 Famagusta, N. CYPRUS

${ }^{5}$ Department of Botany, Faculty of Pharmacy, Ankara University, 06560 Ankara, TURKEY

${ }^{6}$ Department of Biology, Faculty of Arts and Science, Gazi University, 06500, Ankara, TURKEY

*Corresponding author. Email: ilgurbuz@gmail.com; igurbuz@gazi.edu.tr

\begin{abstract}
The aerial part, root and fruits of Ferulago longistylis Boiss. an endemic species, were subjected to the evaluation of essential oil compositions and antimicrobial activity. The essential oils were analyzed by gas chromatography (GC) and gas chromatography-mass spectrometry (GC-MS). The main components of the aerial part were identified as $\alpha$-pinene (18.7\%), bornyl acetate (11.8\%), 2,3,6trimethyl benzaldehyde (9.3\%), $p$-cymene (7.7\%), for the roots, $\alpha$-pinene $(91.7 \%)$; and for the fruits, 2,3,6-trimethyl benzaldehyde (26.5\%), $\alpha$-pinene (14.9\%), (Z)- $\beta$-ocimene (14.1\%), myrcene (7.5\%), sabinene (7.3\%), respectively. The essential oils were evaluated for their in vitro antimicrobial activity against a panel of some human pathogens using a broth microdilution technique resulting in relatively weak antimicrobial and antifungal activity (MIC $1.25-10 \mathrm{mg} / \mathrm{mL}$ ).
\end{abstract}

Keywords: Ferulago longistylis, Apiaceae, essential oil chemistry, antimicrobial activity.

\section{Introduction}

Apiaceae, which is one of the largest plant families in the world, is represented by about 160 endemic species in Turkey (Şenol et al., 2018). New species of Apiaceae family in Turkey are still being discovered (Şenol et al., 2018; Menemen et al., 2018). The Ferulago W. Koch genus is a member of Apiaceae family and 35 taxa grow naturally in Turkey (Güner et al., 2012). The genus Ferulago is an Anatolian-based genus that is very similar to Ferula L. (Özhatay \& Akalın, 2000). One of the 19 endemic Ferulago species in Turkey, F. longistylis Boiss., is among the rare endemics (Güner et al., 2012; Gençler Özkan et al., 2007; Başer \& Kırımer, 2014). Ferulago species are used in Turkish folk medicine for treatment of intestinal worms, hemorrhoids and also used as a tonic, sedative, digestive, however, one of its most significant traditional usage is due to its aphrodisiac activity (Baytop, 1999; Demetzos et al., 2000). Various phytochemical studies revealed that Ferulago species contain mainly coumarins such as bergapten, 8-(1,1-dimethylallyl)bergaptol, bergamotin, isoimperatorin, oxypeucedanin, (-)-prantschimgin and (-)-isovalerylmarmesin (Jimenez et al., 2000), essential oil (major components 2,3,6-trimethylbenzaldehyde, $\alpha$-pinene, ( $Z$ )- $\beta$-ocimene, myrcene, $p$-cymene) (Erdurak et al., 2006; Kılıç et al., 2010; Başer \& Kırımer, 2014), flavonoids such as quercetin and rutin (Khanahmadi et al., 2011) and quinone (1-acetylhydroquinone 4-galactoside) (Doğanca et al., 1991). Additionally, essential oils of different Ferulago species showed antimicrobial activity on various pathogens (Taran et al 2010; Khalighi-Sigarodi et al., 2005; Demirci et al., 2000). 
In this present study, essential oils obtained from 3 different parts (aerial parts, roots and fruits) of $F$. longistylis collected from Refahiye-Erzincan (Turkey) were analyzed for their chemical composition by gas chromatography (GC) and gas chromatography-mass spectrometry (GC-MS). In addition, in vitro antimicrobial activity of all essential oils were evaluated by broth microdilution against various human pathogenic microorganisms.

\section{Materials and Methods}

\section{Plant material and distillation}

F. longistylis was collected from Erzincan-Refahiye, Sakaltutan locality, high mountain steppe, $2030 \mathrm{~m}$ (Turkey) on July 13, 2016. The voucher specimen was identified by one of us HD, and deposited in the Herbarium of Ankara University, Faculty of Pharmacy, Ankara, Turkey (AEF 28777).

The air dried F. longistylis aerial parts, roots and fruits were initially separated. Each plant material was crushed and grinded prior to hydrodistillation which was distilled for $3 \mathrm{~h}$ separately using a Clevenger-type apparatus to produce the essential oils.

\section{Analysis of the essential oils}

\section{GC analysis}

The GC analysis was carried out using an Agilent $6890 \mathrm{~N} \mathrm{GC}$ system. FID detector temperature was $300^{\circ} \mathrm{C}$. To obtain the same elution order with GC-MS, simultaneous auto-injection was done as a duplicate on the same column applying the same operational conditions. Relative percentage amounts of the separated compounds were calculated from FID chromatograms. The results of analysis are given in Table 1.

\section{GC-MS analysis}

An Agilent 5975 GC-MSD system was used, where Innowax FSC column $(60 \mathrm{~m} \times 0.25 \mathrm{~mm}, 0.25 \mu \mathrm{m}$ film thickness) was used with helium as carrier gas $(0.8 \mathrm{~mL} / \mathrm{min})$. GC oven temperature was kept at $60^{\circ} \mathrm{C}$ for 10 min and programmed to $220^{\circ} \mathrm{C}$ at a rate of $4^{\circ} \mathrm{C} / \mathrm{min}$, and kept constant at $220^{\circ} \mathrm{C}$ for $10 \mathrm{~min}$ and then programmed to $240^{\circ} \mathrm{C}$ at a rate of $1^{\circ} \mathrm{C} / \mathrm{min}$. Split ratio was adjusted at $40: 1$. The injector temperature was set to $250^{\circ} \mathrm{C}$. Mass spectra were recorded at $70 \mathrm{eV}$, where the mass range was from $\mathrm{m} / \mathrm{z} 35$ to 450 .

\section{Identification of the components}

Essential oils were analyzed by comparison of their relative retention times (RRT) with those of authentic samples or by comparison of their relative retention index (RRI) to series of $n$-alkanes. Computer matching against commercial (Wiley GC/MS Library, MassFinder Software 4.0) (McLafferty \& Stauffer,1989; Hochmuth, 2008; ESO, 2000) and in-house "Başer Library of Essential Oil Constituents" built up by genuine compounds and components of known oils was used for the identification.

\section{Antimicrobial activity}

\section{Microbial strains}

Standard human pathogenic strains Escherichia coli NRRL B-3008 (Gr -), Salmonella typhimurium ATCC 13311 ( $\mathrm{Gr}-$-), Staphylococcus aureus ATCC $6538(\mathrm{Gr}+$ ), Bacillus subtilis NRRL B-4378 (Gr +); Yeasts: Candida parapsilosis NRRL Y-12696, Candida tropicalis NRRL Y-12968 strains. 


\section{Antimicrobial activity}

The broth microdilution protocol was used (CLSI, 2006, Gençler Özkan et al., 2008). Serial dilutions were performed yielding essential oils concentrations ranging from $0.078-10 \mathrm{mg} / \mathrm{mL}$, for the standard antibacterial and antifungal agents 0.005 to $0.32 \mathrm{mg} / \mathrm{mL}$ were used. DMSO (10\%) and distilled water was used to dissolve essential oils and antibiotics respectively. Microbial suspensions prepared according to McFarland No: 0.5 to adjust to $1 \times 10^{5} \mathrm{CFU} / \mathrm{mL}$ by using tubidometry (Bioland). $10 \mu \mathrm{L}$ microbial suspension were added to each well. All experiments were repeated in duplicates. To prevent the antibacterial activity of neighboring wells from affecting each other, they were covered with a sticky film on the plate. The plates were incubated at $37^{\circ} \mathrm{C}$, for $24 \mathrm{~h}$. Then $20 \mu \mathrm{L}$ resazurin was added to all wells and reproductive wells were stained pink indicating the minimum inhibitory concentrations (MIS), where the average MIC values were calculated based on coloration as shown in Table 3.

\section{Results and Discussion}

Essential oils of aerial parts, roots and fruits of $F$. longistylis were obtained by Clevenger apparatus and essential oil yields were calculated to be $0.27 \%, 0.86 \%$ and $6.1 \%(\mathrm{v} / \mathrm{w})$, respectively. The chemical compositions of all the essential oils obtained were analyzed by GC and GC-MS. As shown in Table 1, seventythree components were identified for the aerial parts, representing $86.7 \%$ of the sample, with $\alpha$-pinene (18.7\%), bornyl acetate (11.8\%), 2,3,6-trimethyl benzaldehyde $(9.3 \%), p$-cymene $(7.7 \%)$ as major constituents. For essential oil of the roots, forty-eight components were identified representing $99.3 \%$ of the sample, with $\alpha$-pinene (91.7\%), $\beta$-pinene (2.0\%), myrcene (1.1\%) as major constituents. For the essential oil of the fruits, thirty-three components were identified, representing $99.1 \%$ of the sample, with 2,3,6-trimethyl benzaldehyde (26.5\%), $\alpha$-pinene (14.9\%), (Z)- $\beta$-ocimene (14.1\%), myrcene $(7.5 \%)$, sabinene $(7.3 \%)$ as main constituents. The chemical composition of all essential oils obtained from different parts of $F$. longistylis are given in Table 1.

Table 1. GC-MS analysis results of essential oil obtained separately from 3 different parts of the $F$. longistylis.

\begin{tabular}{|c|c|c|c|c|c|}
\hline RRI & Compound & FL-AP \% & FL-R \% & FL-F \% & IM \\
\hline 1014 & Tricyclene & $\operatorname{tr}$ & - & - & MS \\
\hline 1032 & $\alpha$-Pinene & 18.7 & 91.7 & 14.9 & $\mathrm{RRI}, \mathrm{MS}$ \\
\hline 1035 & $\alpha$-Thujene & 0.2 & 0.1 & 0.2 & $\mathrm{RRI}, \mathrm{MS}$ \\
\hline 1072 & $\alpha$-Fenchene & - & $\operatorname{tr}$ & - & MS \\
\hline 1076 & Camphene & 0.7 & 0.5 & 0.6 & RRI, MS \\
\hline 1093 & Hexanal & 0.1 & $\operatorname{tr}$ & - & RRI, MS \\
\hline 1118 & $\beta$-Pinene & 0.3 & 2.0 & 0.6 & RRI, MS \\
\hline 1132 & Sabinene & 0.2 & 0.4 & 7.3 & $\mathrm{RRI}, \mathrm{MS}$ \\
\hline 1135 & Thuja-2,4(10)-diene & 0.8 & 0.1 & 0.4 & MS \\
\hline 1174 & Myrcene & 0.2 & 1.1 & 7.5 & MS \\
\hline 1188 & $\alpha$-Terpinene & $\operatorname{tr}$ & - & 0.2 & RRI, MS \\
\hline 1195 & Dehydro-1,8-cineole & 0.1 & - & - & MS \\
\hline 1203 & Limonene & 0.3 & 0.5 & 0.9 & RRI, MS \\
\hline 1218 & $\beta$-Phellandrene & $\operatorname{tr}$ & $\operatorname{tr}$ & 0.1 & RRI, MS \\
\hline 1244 & 2-Pentyl furan & $\operatorname{tr}$ & 0.1 & - & MS \\
\hline 1246 & (Z)- $\beta$-Ocimene & 0.5 & 0.1 & 14.1 & MS \\
\hline
\end{tabular}




\begin{tabular}{|c|c|c|c|c|c|}
\hline 1255 & $\gamma$-Terpinene & 0.9 & 0.1 & 4.0 & RRI, MS \\
\hline 1266 & (E)- $\beta$-Ocimene & 0.3 & $\operatorname{tr}$ & 0.4 & MS \\
\hline 1280 & $p$-Cymene & 7.7 & 0.4 & 0.8 & RRI, MS \\
\hline 1290 & Terpinolene & 0.1 & $\operatorname{tr}$ & 0.1 & RRI, MS \\
\hline 1294 & 1,2,4-Trimethylbenzene & 0.9 & $\operatorname{tr}$ & 0.6 & MS \\
\hline 1355 & 1,2,3-Trimethylbenzene & 0.3 & $\operatorname{tr}$ & - & MS \\
\hline 1429 & Perillene & - & $\operatorname{tr}$ & - & MS \\
\hline 1439 & $\gamma$-Campholene aldehyde & 0.1 & $\operatorname{tr}$ & - & MS \\
\hline 1441 & (E)-2-Octenal & - & $\operatorname{tr}$ & - & MS \\
\hline 1452 & $\alpha, p$-Dimethylstyrene & 0.2 & $\operatorname{tr}$ & - & MS \\
\hline 1477 & 4,8-Epoxy terpinolene & $\operatorname{tr}$ & - & - & MS \\
\hline 1499 & $\alpha$-Campholene aldehyde & 0.1 & 0.2 & - & MS \\
\hline 1522 & Chrysanthenone & - & - & 1.5 & MS \\
\hline 1532 & Camphor & - & $\operatorname{tr}$ & - & RRI, MS \\
\hline 1535 & $\beta$-Bourbonone & 0.4 & - & - & MS \\
\hline 1553 & Linalool & 0.2 & - & 0.1 & RRI, MS \\
\hline 1582 & cis-Chrysanthenyl acetate & 7.5 & 0.2 & 4.2 & MS \\
\hline 1586 & Pinocarvone & - & $\operatorname{tr}$ & - & RRI, MS \\
\hline 1590 & Bornyl acetate & 11.8 & 0.6 & 3.3 & RRI, MS \\
\hline 1611 & Terpinen-4-ol & - & $\operatorname{tr}$ & 0.7 & RRI, MS \\
\hline 1612 & $\beta$-Caryophyllene & 2.1 & - & 0.3 & RRI, MS \\
\hline 1614 & Carvacrol methyl ether & - & 0.1 & - & RRI, MS \\
\hline 1616 & Hotrienol & 0.1 & - & - & MS \\
\hline 1645 & cis-Verbenyl acetate & - & - & 0.7 & MS \\
\hline 1648 & Myrtenal & 0.8 & 0.1 & 0.1 & MS \\
\hline 1655 & (E)-2-Decenal & - & $\operatorname{tr}$ & - & MS \\
\hline 1661 & trans-Pinocarvl acetate & - & - & 0.3 & MS \\
\hline 1663 & cis-Verbenol & 1.8 & $\operatorname{tr}$ & 0.8 & RRI, MS \\
\hline 1670 & trans-Pinocarveol & - & 0.1 & - & RRI, MS \\
\hline 1683 & trans-Verbenol & 5.0 & 0.1 & 3.1 & RRI, MS \\
\hline 1704 & $\gamma$-Curcumene & 0.4 & - & - & MS \\
\hline 1719 & Borneol & 0.4 & $\operatorname{tr}$ & - & RRI, MS \\
\hline 1725 & Verbenone & 0.3 & $t r$ & - & RRI, MS \\
\hline 1726 & Germacrene D & 1.7 & - & 0.4 & MS \\
\hline 1738 & $p$-Mentha-1,5-dien-8-ol & - & - & 1.5 & MS \\
\hline 1740 & $\alpha$-Muurolene & 0.2 & - & - & MS \\
\hline 1760 & Chrysanthenyl isovalerate II & - & - & - & MS \\
\hline 1764 & cis-Chrysanthenol & 0.2 & $\operatorname{tr}$ & - & MS \\
\hline 1764 & (E)-2-Undecenal & - & $\operatorname{tr}$ & - & MS \\
\hline 1779 & $(E, Z)-2,4$-Decadienal & - & $\operatorname{tr}$ & - & MS \\
\hline 1786 & ar-Curcumene & 1.3 & - & - & MS \\
\hline 1797 & $p$-Methyl acetophenone & $\operatorname{tr}$ & - & - & MS \\
\hline
\end{tabular}




\begin{tabular}{|c|c|c|c|c|c|}
\hline 1804 & Myrtenol & 0.1 & - & - & MS \\
\hline 1827 & $(E, E)$-2,4-Decadienal & 0.1 & 0.1 & - & MS \\
\hline 1845 & trans-Carveol & 0.3 & $\operatorname{tr}$ & - & RRI, MS \\
\hline 1849 & Calamenene & $\operatorname{tr}$ & - & - & MS \\
\hline 1849 & Cuparene & 0.1 & - & - & MS \\
\hline 1854 & Germacrene B & - & - & 0.2 & MS \\
\hline 1864 & p-Cymen-8-ol & 0.4 & $\operatorname{tr}$ & 0.1 & MS \\
\hline 1868 & (E)-Geranyl acetone & $\operatorname{tr}$ & - & - & MS \\
\hline 1878 & 2,5-Dimethoxy-p-cymene & 0.8 & 0.1 & - & MS \\
\hline 1925 & 2,3,4-Trimethyl benzaldehyde & 1.8 & $\operatorname{tr}$ & 2.6 & MS \\
\hline 1945 & 1,5-Epoxy-salvial-4(14)-ene & 0.1 & - & - & MS \\
\hline 1958 & (E)- $\beta$-lonone & 0.1 & - & - & MS \\
\hline 2008 & Caryophyllene oxide & 2.7 & - & - & RRI, MS \\
\hline 2019 & 2,3,6-Trimethyl benzaldehyde & 9.3 & 0.2 & 26.5 & MS \\
\hline 2037 & Salvial-4(14)-en-1-one & 0.1 & - & - & MS \\
\hline 2050 & (E)-Nerolidol & 0.1 & - & - & MS \\
\hline 2071 & Humulen epoxide-II & 0.3 & - & - & MS \\
\hline 2084 & Octanoic acid & 0.1 & - & - & RRI, MS \\
\hline 2131 & Hexahydro farnesyl acetone & $\operatorname{tr}$ & - & - & MS \\
\hline 2144 & Spathulanol & 0.3 & - & - & MS \\
\hline 2148 & (Z)-3-Hexen-1-ol benzoate & 0.3 & - & - & MS \\
\hline 2232 & $\alpha$-Bisabolol & $\operatorname{tr}$ & - & - & RRI, MS \\
\hline 2255 & $\alpha$-Cadinol & $\operatorname{tr}$ & - & - & MS \\
\hline 2278 & Torilenol & 0.2 & - & - & MS \\
\hline 2324 & Caryophylladienol II & 0.2 & - & - & MS \\
\hline 2369 & Eudesma-4(15)7-dien-1- $\beta$-ol & 0.4 & - & - & MS \\
\hline 2392 & Caryophyllenol II & 0.3 & - & - & MS \\
\hline 2500 & Pentacosane & 0.1 & - & - & RRI, MS \\
\hline 2622 & Phytol & 0.5 & - & - & MS \\
\hline 2655 & Benzyl benzoate & 0.4 & - & - & RRI, MS \\
\hline 2670 & Tetradecanoic acid & - & $\operatorname{tr}$ & - & $\mathrm{RRI}, \mathrm{MS}$ \\
\hline 2900 & Nonacosane & 0.3 & - & - & RRI, MS \\
\hline \multirow[t]{3}{*}{2931} & Hexadecanoic acid & 0.4 & 0.4 & - & RRI, MS \\
\hline & Yield (\%) & 0.27 & 0.86 & 6.1 & \\
\hline & Total & 86.7 & 99.3 & 99.1 & \\
\hline
\end{tabular}

RRI: Relative retention indices calculated against $n$-alkanes; \%: calculated from FID data; $t$ : Trace (< $0.1 \%)$; MS: identified on the basis of computer matching of the mass spectra with those of the Wiley and MassFinder libraries and comparison with literature data, FL-AP: F. longistylis aerial part; FL-R: F. longistylis roots; FL-F: F. longistylis fruits.

After analyzing the composition of the obtained essential oils, potential antibacterial and antifungal activities were also evaluated against four bacteria and 2 yeast by broth microdilution method. The minimum inhibitor concentration of the essential oils is given in Table 2. As shown in Table 2, all essential oil samples showed 
anticandidal activity at $1.25-10 \mathrm{mg} / \mathrm{mL}$ MIC values. However, root essential oil showed antibacterial or antifungal activity at $1.25-5 \mathrm{mg} / \mathrm{mL}$ MIC values against all tested microorganism.

$\alpha$-pinene, one of the major components of essential oils from $F$. longistylis, might be responsible for this activity. Although there are papers stating that $\alpha$-pinene has antibacterial effect (Aligiannis et al., 2001; Leite et al., 2007), there are also some papers claiming the opposite (Koutsoudaki et al., 2005; Zore et al., 2011). This is explained by the fact that only the (-)- $\alpha$-pinene of the enantiomers has this effect. Furthermore, $p$ cymene affects Gram (-) bacteria by disrupting the membrane structure (Ultee et al., 2002).

There are 2 studies on the essential oil of $F$. longistylis in the literature. In these studies, fruits (Gençler Özkan et al., 2008) and aerial parts (Kılıç et al., 2010) of $F$. longistylis were collected from the same locality (on July, 2006) and the essential oil composition was determined by GC and GC/MS. Essential oil yield obtained from the fruits of the F. longistylis was reported to be $6.4 \%$ (Gençler Özkan et al., 2008). Fifty-nine components were identified representing $96.7 \%$ of the essential oil of the fruits and major components were determined to be 2,3,6-trimethylbenzaldehyde (29.4\%), $\alpha$-pinene (16.7\%), (Z)- $\beta$-ocimene (15.9\%), sabinene (6.2\%), myrcene $(5.7 \%)$ and bornyl acetate (4.4\%). These values are quite consistent with our findings for the essential oil of the fruits (2,3,6-trimethyl benzaldehyde $26.5 \%$, $\alpha$-pinene $14.9 \%$, (Z)- $\beta$-ocimene $14.1 \%$, myrcene $7.5 \%$, sabinene $7.3 \%$, bornyl acetate $3.3 \%$ ). Furthermore, thuja-2,4(10)diene (0.4\%), chrysanthenone $(1.5 \%)$ and some other components ( $0.1 \%$ or less) were found in the present study.

Gençler Özkan et al. (2008) also studied the antibacterial and antifungal activity of the essential oil obtained from $F$. longistylis fruits and stated that it had a weak activity $(0.5-1.0 \mathrm{mg} / \mathrm{mL}$, MIC values) similar to our results (Table 2). However, there are also minor differences between the composition and antimicrobial effects of essential oils in both studies. The minor changes in the composition of essential oils can be considered to cause minor changes in the antimicrobial effect, as reported here.

For aerial parts, essential oil yield was $0.16 \%$ and fifty-nine components representing $92.5 \%$ of the essential oil were identified (Kılıç et al., 2010). Major components were 2,3,6-trimethyl benzaldehyde (32.7\%), bornyl acetate (12.6\%), $p$-cymene (11.9\%), cis-chrysanthenyl acetate (4.2\%), $\alpha$-pinene (3.5), 2,3,4-trimethyl benzaldehyde (3.1\%), (Z)- $\beta$-ocimene (2.3\%). It is observed that the amounts of $\alpha$-pinene $(18.7 \%)$ and 2,3,6trimethyl benzaldehyde (9.3\%) are quite different from the present study. In addition, thuja-2,4(10)diene (0.8\%), linalool (0.2\%), trans-verbenol (5.0\%), germacrene D (1.7\%), $\alpha$-muurolene $(0.2 \%), 2,5$-dimethoxy- $p$ cymene $(0.8 \%)$, spathulanol $(0.3 \%)$, torilenol $(0.2 \%)$ were additionaly determined in our present study. It is thought that possible change of some factors (environmental conditions, climatic conditions, pollution etc.) may result in differences in the chemical composition of essential oils (Figueiredo et al., 2008). The literature data and the results of the present study show that major compounds of the essential oil obtained from $F$. longistylis are $\alpha$-pinene, 2,3,6-trimethylbenzaldehyde, (Z)- $\beta$-ocimene, myrcene, bornyl acetate, sabinene, $p$ cymene (Gençler Özkan et al., 2008; Kılıç et al., 2010).

When the previous studies on $F$. longistylis were reviewed, it was seen that the essential oils obtained from only aerial parts or fruits were analyzed in these studies (Gençler Özkan et al., 2008; Kılıç et al., 2010). Again, it was seen that the only antimicrobial effect of the essential oil obtained only from the fruits was studied. 
Table 2. Antimicrobial activity results (MIC, $\mathrm{mg} / \mathrm{mL}$ )

\begin{tabular}{llcccccc}
\hline Microorganisms & Strain Numbers & FL-AP $^{\mathbf{a}}$ & FL-R $^{\mathbf{b}}$ & FL-F $^{\mathbf{c}}$ & AMOX $^{\mathbf{d}}$ & CLO $^{\mathbf{e}}$ & FLC $^{\mathbf{f}}$ \\
\hline Escherichia coli & NRRL B-3008 & - & 5 & 10 & 0.01 & 0.01 & - \\
Staphylococcus aureus & ATCC 6538 & - & 5 & - & - & 0.01 & - \\
Salmonella typhimurium & ATCC 13311 & 10 & 5 & - & - & 0.4 & - \\
Bacillus subtilis & NRRL B-4378 & - & 2.5 & - & - & 0.01 & - \\
Candida tropicalis & NRRL Y-12968 & 10 & 1.25 & 10 & - & - & 0.08 \\
Candida parapsilosis & NRRLY-12696 & 5 & 1.25 & 5 & - & - & 0.005 \\
\hline
\end{tabular}

${ }^{\text {a }}$ F. longistylis aerial part essential oil; ${ }^{b}$ F. longistylis root essential oil; ${ }^{c}$ F. longistylis fruit essential oil; ${ }^{d}$ amoxicillin; ${ }^{e}$ chloramphenicol; ffluconazole.

In the present study, the volatile oils were obtained from 3 different parts (aerial parts, fruits and roots) of $F$. longistylis and antimicrobial effects were studied against various human pathogens. To the best of our knowledge, composition of the essential oil obtained from the roots of the $F$. longistylis and its antimicrobial effect have been evaluated for the first time. Furthermore, antimicrobial effect of the essential oil obtained from the aerial parts was determined for the first time.

\section{ACKNOWLEDGEMENTS:}

This study is financially supported by TUBITAK (Project no: 115S364). The authors would like to thank Msc. Bio. Melek Tekgöz (Department of Biology, Eskisehir Technical University) for her assistance in the experiments.

\section{REFERENCES}

Aligiannis, N., Kalpoutzakis, E., Chinou, I. B., Mitakou, S., Gikas, E., \& Tsarbopoulos, A. (2001). Composition and antimicrobial activity of the essential oils of five taxa of Sideritis from Greece. Journal of Agricultural and Food Chemistry, 49(2), 811-815.

Başer, K. H. C., \& Kırımer, N. (2014). Essential oils of Anatolian Apiaceae - A profile. Natural Volatiles \& Essential Oils, 1(1), 1-50.

Baytop, T. (1999). Therapy with Medicinal Plants in Turkey Past and Present. Istanbul: Nobel Tıp Publications.

CLSI (NCCLS) M7-A7. (2006). Methods for dilution antimicrobial susceptibility tests for bacteria that grow aerobically; approved standard, seventh edition, Wayne, USA.

Demetzos, C., Perdetzoglou, D., Gazouli, M., Tan, K., \& Economakis, C. (2000). Chemical analysis and antimicrobial studies on three species of Ferulago from Greece. Planta Medica, 66(06), 560-563.

Demirci, F., İşcan, G., Güven, K., Kırımer, N. Demirci, B., \& Başer, K.H.C. (2000). Antimicrobial activities of Ferulago essential oils. Zeitschrift für Naturforschung C, 55(11-12), 886-889.

Doğanca, S., Ulubelen, A., \& Tuzlacı, E. (1991). 1-Acetylhydroquinone 4-galactoside from Ferulago aucheri. Phytochemistry, 30(8), 2803-2805.

Erdurak, C. S., Coşkun, M., Demirci, B., \& Başer, K. H. C. (2006). Composition of the essential oil of fruits and roots of Ferulago isaurica Peşmen and F. syriaca Boiss.(Umbelliferae) from Turkey. Flavour and Fragrance Journal, 21(1), 118121.

ESO 2000, 1999. The Complete Database of Essential Oils, Boelens Aroma Chemical Information Service. The Netherlands.

Figueiredo, A. C., Barroso, J. G., Pedro, L. G., \& Scheffer, J. J. (2008). Factors affecting secondary metabolite production in plants: volatile components and essential oils. Flavour and Fragrance journal, 23(4), 213-226. 
Gençler Özkan, A. M., Demirci, B., Demirci, F., \& Başer, K. H. C. (2008). Composition and antimicrobial activity of essential oil of Ferulago longistylis Boiss. Fruits. Journal of Essential Oil Research, 20(6), 569-573.

Güner, A., Aslan, S., Ekim, T., Vural, M., \& Babac, M. T. (2012). Turkey Plant List (Vascular Plants). İstanbul: Nezahat Gökyiğit Botanical Garden and Flora Research Association Publication.

Hochmuth, D. H. (2008). MassFinder 4.0, Hochmuth Scientific Consulting, Hamburg, Germany.

Jiménez, B., Grande, M. C., Anaya, J., Torres, P., \& Grande, M. (2000). Coumarins from Ferulago capillaris and F. brachyloba. Phytochemistry, 53(8), 1025-1031.

Khalighi-Sigaroodi, F., Hadjiakhoondi, A., Shahverdi, A. R., Mozaffarian, V. A., \& Shafiee, A. (2005). Chemical composition and antimicrobial activity of the essential oil of Ferulago bernardii Tomk. and M. Pimen. Daru Journal of Pharmaceutical Science, 13, 100-104.

Khanahmadi, M., Shahrezaei, F., \& Alizadeh, A. (2011). Isolation and structural elucidation of two flavonoids from Ferulago angulata (Schlecht) Boiss. Asian Journal of Research in Chemistry, 4(11), 1667-1670.

Kılıç, C. S., Özkan, A. M. G., Demirci, B., Coşkun, M., \& Başer, K. H. C. (2010). Essential oil composition of four endemic Ferulago species growing in Turkey. Natural Product Communications, 5(12), 1951- 1954.

Koutsoudaki, C., Krsek, M., \& Rodger, A. (2005). Chemical composition and antibacterial activity of the essential oil and the gum of Pistacia lentiscus var. chia. Journal of Agricultural and Food Chemistry, 53(20), 7681-7685.

Leite, A. M., Lima, E. D. O., Souza, E. L. D., Diniz, M. D. F. F. M., Trajano, V. N., \& Medeiros, I. A. D. (2007). Inhibitory effect of beta-pinene, alpha-pinene and eugenol on the growth of potential infectious endocarditis causing Grampositive bacteria. Revista Brasileira de Ciencias Farmaceuticas, 43(1), 121-126.

McLafferty, F. W., \& Stauffer, D. B. (1989). The Wiley/NBS Registry of Mass Spectral Data, J Wiley and Sons, New York, USA.

Menemen, Y., Cingay, B., Çimen, A. O., \& Ertaş S., (2018). A new species of Cymbocarpum (Apiaceae) from the Central Anatolia Region of Turkey and its phylogenetic position within Tordylieae. Turkish Journal of Botany, 42(1), 91-99.

Özhatay, N., \& Akalın, E. (2000). A new species of Ferulago W. Koch (Umbelliferae) from north-west Turkey. Botanical Journal of the Linnean Society, 133(4), 535-542.

Şenol, S. G., Eroğlu, V., Pelit, N. B., \& Bozyel, D. (2018). Ekimia ozcan-secmenii (Apiaceae), a new species from Southwest Anatolia, Turkey. Turkish Journal of Botany, 42(4), 510-517.

Stamenkovic, J. G., Petrovic, G. M., Jovanovic, O. P., Ickovski, J. D., Palic, I. R., \& Stojanovic, G. S. (2019). Chemical composition of the essential oils and headspace volatiles of Ferulago sylvatica (Besser) Reichenb. from Serbia. Natural Product Research, 1-4. https://doi.org/10.1080/14786419.2019.1566723

Taran, M., Ghasempour, H. R., \& Shirinpour, E. (2010). Antimicrobial activity of essential oils of Ferulago angulata subsp. carduchorum. Jundishapur Journal of Microbiology, 3, 10.

Ultee, A., Bennik, M. H. J., \& Moezelaar, R. J. A. E. M. (2002). The phenolic hydroxyl group of carvacrol is essential for action against the food-borne pathogen Bacillus cereus. Applied Environmental Microbiology, 68(4), 1561-1568.

Zore, G. B., Thakre, A. D., Jadhav, S., \& Karuppayil, S. M. (2011). Terpenoids inhibit Candida albicans growth by affecting membrane integrity and arrest of cell cycle. Phytomedicine, 18(13), 1181-1190. 